\title{
The Coronavirus Membrane Glycoprotein
}

\author{
Peter J. M. RotTier
}

\section{INTRODUCTION}

Coronaviruses have a simple protein composition. While there is some variation among different members, a basic set of four protein species universally occurs: the nucleocapsid protein $(\mathrm{N})$, the spike protein $(\mathrm{S})$, a small membrane protein $(\mathrm{SM})$, and the membrane glycoprotein (M). Some coronaviruses have an additional membrane glycoprotein (HE). The $M$ protein, previously also called $\mathrm{El}$, is the subject of this chapter. As will become clear, $\mathrm{M}$ is a peculiar glycoprotein, different from all other viral glycoproteins in its structural and biochemical features. These unique features may be responsible for important biological properties of coronaviruses, in particular for their intracellular budding.

$M$ is the most abundant virion protein. In murine hepatitis virus (MHV) it was estimated by isotopic labeling to comprise some $40 \%$ of the particle's protein mass, exceeding the nucleocapsid protein on a molar basis at a ratio of $2: 1$ (Sturman et al., 1980). A similar ratio was obtained from incorporation studies with avian infectious bronchitis virus (IBV) (Stern et al., 1982), while equimolar ratios were determined for bovine coronavirus (BCV) (King and Brian, 1982) and human coronavirus (HCV) OC43 (Hogue and Brian, 1986). In the latter case, $M$ and $N$ were calculated to be present at a rate of 726 molecules per virion.

The $M$ gene, together with the genes for the other structural proteins, is located in the $3^{\prime}$ one third of the coronaviral genome, downstream from the spike protein gene and upstream from the nucleoprotein gene. As a conse-

PETER J. M. ROTTIER - Institute of Virology, Department of Infectious Diseases and Immunology, University of Utrecht, 3584 CL Utrecht, The Netherlands.

The Coronaviridae, edited by Stuart G. Siddell, Plenum Press, New York, 1995. 
quence of the specific mode of transcription of coronaviruses, the $M$ protein is expressed from a mRNA that, in addition to the $M$ sequence, carries extra genetic information including the $\mathrm{N}$ sequence. This additional information is located $3^{\prime}$ from the $M$ gene and is functionally redundant; the $M$ protein is equally well translated from a mRNA derived from a cloned copy of the M gene (see Machamer and Rose, 1987; Mayer et al., 1988; Rottier and Rose, 1987).

\section{PHYSICOCHEMICAL PROPERTIES}

\section{A. Covalent Modifications}

The M protein is usually found as a family of differentially glycosylated proteins, including the unglycosylated precursor. These proteins span a $M_{r}$ range of 20 to $38 \mathrm{kDa}$. The $\mathrm{M}$ protein of a particular coronavirus carries either $\mathrm{N}$ or O-linked oligosaccharides (Table I). The only other modification identified so far is the addition of sulfate (Garwes et al., 1976), but it is unknown whether this constituent is attached to the oligosaccharide side chains or bound directly to the polypeptide through tyrosine. $M$ is not acylated (Niemann and Klenk, 1981; Schmidt, 1982), nor does it contain phosphate (e.g., Stohlman and Lai, 1979; Rottier et al., 1981a; King and Brian, 1982; Hogue and Brian, 1986).

The structures of the $\mathrm{N}$-linked oligosaccharides carried by coronavirus $\mathrm{M}$ proteins have not been studied in detail, but are probably not different from those found in other viral and cellular N-glycosylated proteins. Carbohydrates bound to a polypeptide through O-linkage to serine or threonine residues are quite uncommon among viral proteins. Of the O-glycosylated coronaviral $\mathrm{M}$ proteins, the side chains of the M protein of MHV strain A59 grown in 17C11 cells, a spontaneously transformed BALBC/3T3 line, have been analyzed (Niemann and Klenk, 1981; Niemann et al., 1984). Two size classes of oligosaccharides were released from the protein by $\beta$-elimination. Their structures, as

TABLE I. Type of Glycosylation of M Proteins of Coronaviruses

\begin{tabular}{ll}
\hline Common name & Designation \\
\hline N-glycosylation & \\
Canine coronavirus & CCV \\
Feline infectious peritonitis virus & FIPV \\
Feline enteric coronavirus & FECV \\
Human coronavirus strain 229E & HCV-229E \\
Infectious bronchitis virus & IBV \\
Turkey coronavirus & TCV \\
Transmissible gastroenteritis virus & TGEV \\
O-glycosylation & \\
Bovine coronavirus & BCV \\
Diarrhoea virus of infant mice & DVIM \\
Human coronavirus strain OC43 & HCV-OC43 \\
Mouse hepatitis virus & MHV \\
\hline
\end{tabular}



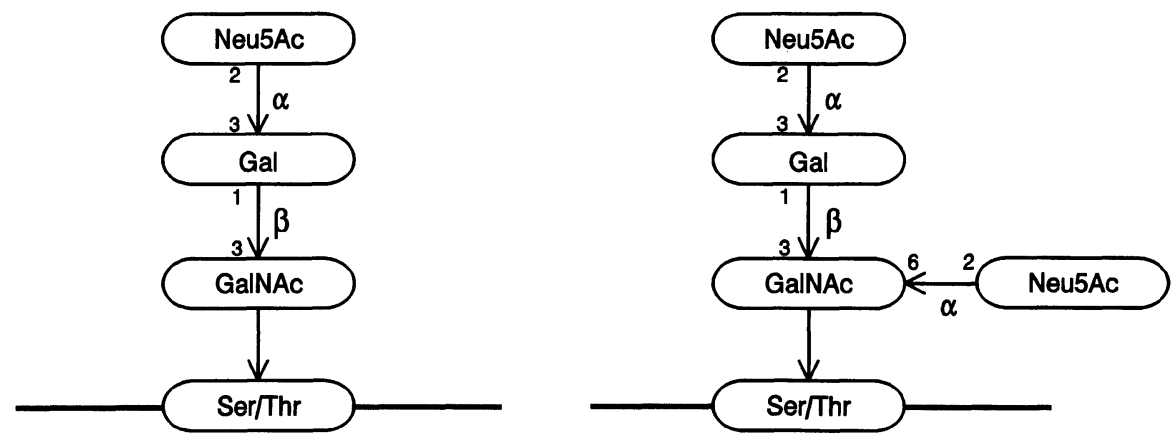

FIGURE 1. Structures of the O-linked oligosaccharide side chains of the MHV-A59 M glycoprotein.

determined by a combined gas chromatographic and mass spectrometric analysis, are shown in Fig. 1. The branched form was most abundant, comprising about $65 \%$ of the carbohydrate structures. Both forms were attached to the $\mathrm{M}$ polypeptide via $N$-acetylgalactosamine. Of the sialic acids ( $N$-acetylneuraminic acid, Neu5Ac), some $20 \%$ were identified as the O-acetylated derivative Neu5,9Ac (Niemann et al., 1984).

The oligosaccharides are attached to the $\mathrm{N}$-terminal region of the $\mathrm{M}$ molecule and exposed at the virion surface. Treatment of MHV (Sturman, 1977; Sturman and Holmes, 1977; Rottier et al., 1984) and BCV (King and Brian, 1982) with various proteases removed some $5 \mathrm{kDa}$ from the polypeptide, including all the O-linked sugars. Similarly, the N-linked oligosaccharides of the IBV M protein were all detached by hydrolysis of the exposed domain of the molecule (Cavanagh, 1981; Cavanagh et al., 1986a). Using [ $\left.{ }^{35} \mathrm{~S}\right]$ formyl-methionine to terminally label the polypeptide, this ectodomain was identified as the N-terminus (Stern et al., 1982; Rottier et al., 1984).

\section{B. Solubility}

The $M$ protein has unusual solubility properties. This was demonstrated for MHV M in the pioneering studies of Sturman and Holmes (Sturman, 1977, 1981; Sturman and Holmes, 1977; Sturman et al., 1980). When isolated at $4{ }^{\circ} \mathrm{C}$ from virions after nonionic detergent solubilization of the viral membrane, the protein formed globular, irregular aggregates of various sizes. Raising the temperature to $37^{\circ} \mathrm{C}$ induced a conformational change in the molecules that led the aggregates to associate with the nucleocapsid through interaction with the viral RNA (Sturman et al., 1980). Thermosensitivity of the $M$ protein was also prominent in sodium dodecyl sulfate (SDS) solution: heating from $25^{\circ} \mathrm{C}$ or $37^{\circ} \mathrm{C}$, in which range the protein is in a monomeric state, to $100^{\circ} \mathrm{C}$ resulted in the formation of various self-aggregates, an effect that was even more pronounced in the presence of reducing agents (Sturman, 1977; Sturman and Holmes, 1977). Unlike the M protein of the MHV-A59 strain, the M protein of MHV-JHM additionally appeared to form heterogeneous complexes with the $S$ glycoprotein under these conditions (Wege et al., 1979; Siddell et al., 1981). The 
tendency of the MHV M protein to aggregate was also observed after various other denaturing treatments (Sturman, 1977). Apparently, any condition that promotes the unfolding of the $M$ protein can expose a (probably hydrophobic) domain of the molecule which then engages in interactions.

Aggregation of $M$ in SDS has been described for a number of other coronaviruses such as hemagglutinating encephalitis virus (HEV) (Callebaut and Pensaert, 1980), HCV-OC43 (Schmidt and Kenny, 1982; Hogue and Brian, 1986), and BCV (Niemann and Klenk, 1981; Deregt et al., 1987). On the other hand, it is not a universal feature as the effect was not observed after heat denaturation of the M polypeptide of IBV (Cavanagh, 1981; Stern and Sefton, 1982b) or HCV-229E (Schmidt and Kenny, 1982), not even in the presence of 2-mercaptoethanol. The reason for this variable behavior is not understood. The effect seems to be independent of the degree and type of glycosylation. Even complete removal of the $\mathrm{N}$-terminal ectodomain did not abolish the aggregation properties of the polypeptide (Sturman, 1977).

\section{PROTEIN STRUCTURE}

\section{A. Primary Structure}

During the past years, the $M$ genes of several coronaviruses have been sequenced. The deduced amino acid sequences of a number of $M$ proteins are compiled in the alignment presented in Fig. 2. The primary structures are 225230 amino acids long, with the exception of the transmissible gastroenteritis virus (TGEV) and feline infectious peritonitis virus (FIPV) sequences which amount to 262 residues, due to an extension at the $\mathrm{NH}_{2}$-terminus. The polypeptides are slightly basic with net charges at neutral $\mathrm{pH}$ ranging from +4 (HCV-229E) to +9 (BCV). Their cysteine content is quite variable, with only two such residues in the HCV-229E sequence and nine residues in IBV M. These numbers do not explain the effects of reducing agents on the solubility of the coronavirus $\mathrm{M}$ proteins.

Pairwise sequence comparisons support the long-standing classification of coronaviruses made on the basis of antigenic relationships (McIntosh et al., 1969; Bradburne, 1970; Pedersen et al., 1978; Horzinek et al., 1982). The M proteins of $\mathrm{MHV}$ and $\mathrm{BCV}$, viruses of the same antigenic subgroup, are very closely related ( $86 \%$ identity), but differ largely from all the others (e.g., $\mathrm{MHV}$ / IBV $29 \%$, MHV/HCV-229E 32\%, MHV/FIPV 36\%). Similarly, the M sequences of TGEV and FIPV, also antigenically related viruses, show a strong homology ( $84 \%$ identity), but are only distantly related to the others (e.g., TGEV/IBV $17 \%$ ). The avian IBV M polypeptide has only low homologies to the mammalian proteins (e.g., IBV/FIPV 20\% identity), in agreement with it being classified separately. HCV-229E has previously been placed into the TGEV group on the basis of weak serological cross-reactivities (Pedersen et al., 1978; Macnaughton, 1981). The M protein of this virus has only little sequence similarity with the TGEV or FIPV protein (e.g., HCV-229E/TGEV 44\% identity) or with any of the other M proteins. The same holds true for the S proteins (Wesseling et al., 1994). The data therefore support the recent proposition by Sanchez et al. (1990) to 
1

70

MHV

BCV

HCV

IBV

FIPV

TGEV

Consensus

.

$\ldots \ldots \ldots \ldots \ldots \ldots \ldots \ldots \ldots \ldots \ldots \ldots \ldots \ldots+\ldots \ldots$ MSVTTPA PVYTWTADEA IKFLKEWNFS LGIILLFITI

$\ldots \ldots \ldots \ldots \ldots \ldots \ldots \ldots \ldots \ldots \ldots \ldots \ldots \ldots \ldots \ldots \ldots$ MSNDTGDI VTHLKNWNFG WNVILTIFIV

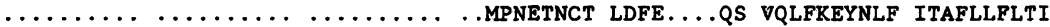

MKYILLILAC IIACVYGERY CAMQ.DSGLQ CINGTNSRCQ TCFE. .RGDL IWHLANWNFS WSVILIVFIT

MK.ILLILAC VIACACGERY CAMKSDTDLS CRNSTASDCE SCFN. .GGDL IWHLANWNFS WSIILIVFIT

71

140

MHV ILQFGYTSRS MFIYVVKMII LWLMWPLTIV LCIFN. .CVY ALNN.VYLGF SIVFTIVSIV IWIMYFVNSI BCV ILQFGYTSRS MFVYVIKMII LWLMWPLTII LTIFN..CVY ALNN.VYLGF SIVFTIVAII MWIVYFVNSI HCV ILQFGHYKYS RLFYGLKMLV LWLLWPLVLA LSIFDTWANW D.SNWAFVAF SFFMAVSTLV MWVMYFANSF IBV ILQYGYATRS KVIYTLKMIV LWCFWPLNIA VGVIS..CTY PPNTGGLVA. AIILTVFACL SFVGYWIQSI FIPV VLQYGRPQFS WLVYGIKMLI MWLLWPIVLA LTIFNAYSEY QVSRYVMFGF SVAGAVVTFA LWMMYFVRV TGEV VLQYGRPQFS WFVYGIKMLI MWLLWPVVLA LTIFNAYSEY QVSRYVMFGF SIAGAIVTFV LWIMYFVRSI

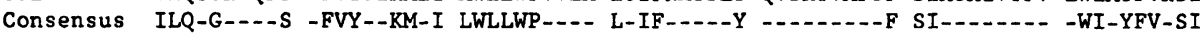

\begin{tabular}{|c|c|c|c|c|c|c|c|}
\hline & 141 & & & & & & 210 \\
\hline MHV & RLFIRTGSWW SFNPETNNLM & CIDMKGTVYV & RPIIEDYHTL & TATIIRGHLY & MQGVKLGTGF & \multirow{2}{*}{\multicolumn{2}{|c|}{ SLSDLPAYVT }} \\
\hline BCV & RLFIRTGSWW SFNPETNNLM & CIDMKGRMYV & RPIIEDYHTL & TVTIIRGHLY & MQGIKLGTGY & & \\
\hline HCV & RLFRRARTFW AWNPEVNAIT & VTTVLGQTYY & QPIQQAPTGI & TVTLLSGVLY & VDGHRLASGV & \multicolumn{2}{|c|}{ QVHNLPEYMT } \\
\hline IBV & RLFKRCRSWW SFNPESNAVG & SILLTNGQQC & NFAIESVPMV & LSPIIRNGVL & YCEGQWLAKC & \multicolumn{2}{|c|}{ EPDHLPKDIF } \\
\hline FIPV & QLYRRTKSWW SFNPETNAIL & CVNALGRSYV & LPLDGTPTGV & TLTLLSGNLY & AEGFKMAGGL & \multirow{2}{*}{\multicolumn{2}{|c|}{$\begin{array}{l}\text { TIEHLPKYVM } \\
\text { NIDNLPKYYM }\end{array}$}} \\
\hline TGEV & QLYRRTNSWW SFNPETKAIL & CVSALGRSYV & LPLEGVPTGV & TLTLLSGNLY & AEGFKIADGM & & \\
\hline onsensus & -LF-R--SWW SFNPE-N--- & $-I---G--Y-$ & $-P--\cdots-$ & $T-T---G-L Y$ & $--G----G-$ & \multicolumn{2}{|c|}{$---L P-Y V-$} \\
\hline & 211 & & & & \multicolumn{3}{|c|}{272} \\
\hline dV & VAKVSHLCTY $\mathrm{K}$. . RAFLDK & VDGVSGFAVY & VKSK. . . VG & NYRLPSNKPS & G. .ADTALLR & I & \\
\hline CV & VAKVSHLLTY KR.GF..LDK & IGDTSGFAVY & VKSKV. ...G & NYRLPSTQKG & SGMDTALLRN & N] & \\
\hline $\mathrm{cV}$ & VAVPSTTIIY SRVGR..SVN & SQNCTGWVFY & VRVKH....G & DFSAVSSPMS & NMTENERLLH & ? & \\
\hline $3 \mathrm{~V}$ & VCTPDRRNIY RMVQKYTGDQ & SGNKKRFATF & VYAKQSVDTG & ELESVATGGS & SLYT . . . . . & & \\
\hline PV & IATPSRTIVY TLVGK. .QLK & ATTATGWAYY & VKSKA....G & DYST. EARTD & NLSEHEKLLH & & \\
\hline EV & VALPSRTIVY TLVGK..KLK & ASSATGWAYY & VKSKA....G & DYST.EARTD & NLSEQEKLLH & MV & \\
\hline
\end{tabular}

FIGURE 2. Sequence alignment of the M proteins of MHV-A59 (Armstrong et al., 1984), BCV (Lapps et al., 1987), HCV-229E (Raabe and Siddell, 1989), IBV (Baudette strain; Boursnell et al., 1984), FIPV (Vennema et al., 1991a), and TGEV (Laude et al., 1987). Not included are the recently determined sequences of TCV (Verbeek and Tijssen, 1991), HCV-OC43 (Mounir and Talbot, 1992), CCV (Horsburgh et al., 1992), and FECV (A. Herrewegh, H. Vennema, R. de Groot, and P. Rottier, unpublished data). Comparison shows the former two to be very similar to the sequences of MHV and $\mathrm{BCV}$, while the latter have a high similarity to the sequences of FIPV and TGEV.

classify HCV-229E in a distinct taxonomic cluster; this suggestion was based on an extensive antigenic comparison of coronaviruses using monoclonal antibodies (see Chapter 1).

As indicated by its solubility, $\mathrm{M}$ is a very hydrophobic protein. It contains $44-51 \%$ of hydrophobic amino acids which are concentrated in the $\mathrm{NH}_{2}$ terminal half of the molecule (Fig. 3). Despite the high degree of sequence variation between the coronavirus $M$ polypeptides, the hydropathicity profiles are remarkably similar. The dominant common feature is the occurrence of three hydrophobic domains alternating with short hydrophilic regions. In the TGEV and FIPV sequence a fourth hydrophobic domain is present at the $\mathrm{NH}_{2}$ terminus, which functions as a cleavable membrane insertion signal (Kapke et al., 1988; Vennema et al., 1991b). In the other M proteins, no such signal appears to be operative; rather, these proteins have a hydrophilic amino terminus. The carboxy terminal half of all $\mathrm{M}$ proteins is amphiphilic, with a hydrophilic domain at the carboxy end.

In view of the large differences in primary sequences, the surprising conser- 

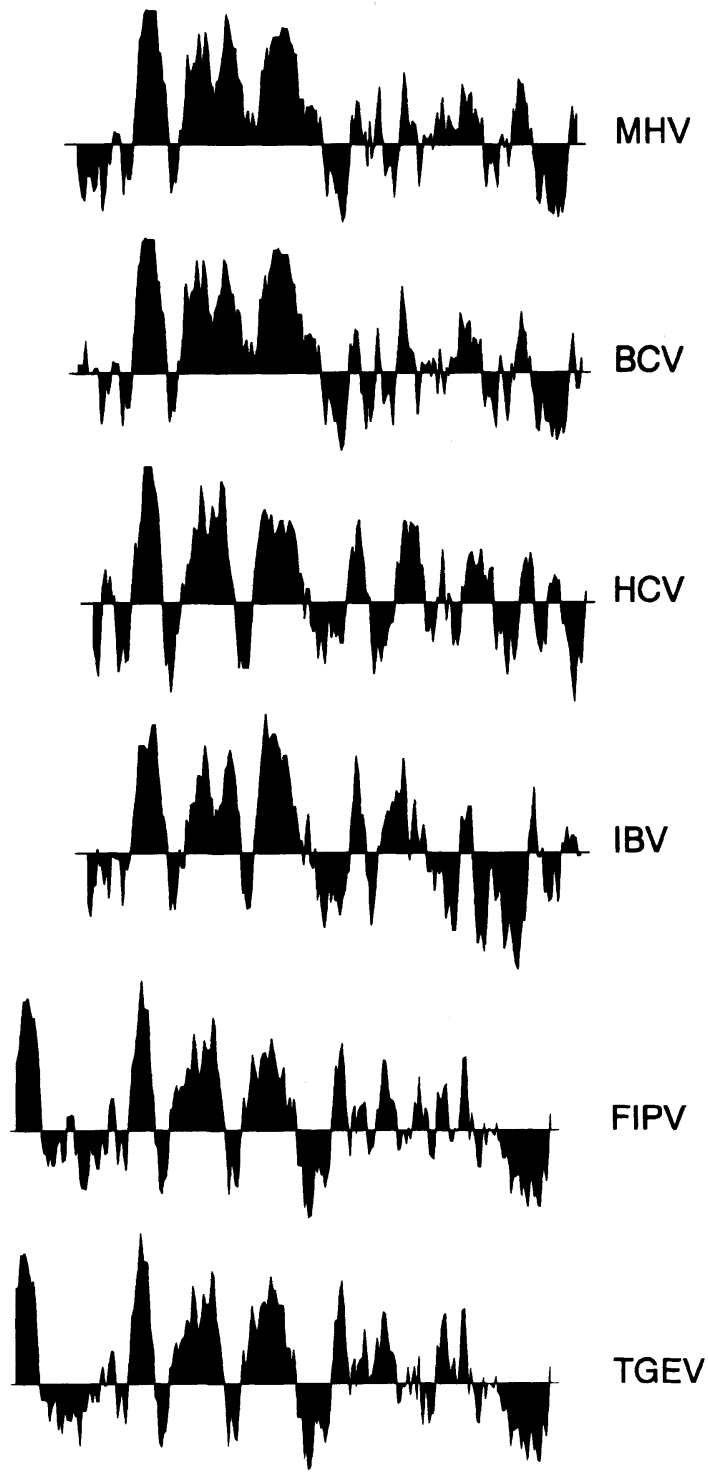

FIGURE 3. Hydropathicity profiles of $\mathrm{M}$ proteins from MHV-A59, BCV, HCV229E, IBV, FIPV, and TGEV determined according to Kyte and Doolittle (1982) using a seven residue moving window. Peaks extending upward indicate hydrophobic regions, downward peaks correspond to hydrophilic regions.

vation of the overall chemical features indicates that there are rigid structural constraints on $\mathrm{M}$ as a result of functional requirements. The highest levels of sequence conservation appear in the hydrophobic regions and in the center of the polypeptide directly adjacent to the third internal hydrophobic region, where a stretch of 8 amino acids is extremely well conserved /see consensus in Fig. 2). This suggests a selective pressure on these domains for the maintenance of important structural characteristics.

As mentioned above, coronavirus $\mathrm{M}$ proteins are glycosylated in their $\mathrm{NH}_{2}$ terminal ectodomain, i.e., the hydrophilic domain preceding the first internal 
hydrophobic region (see Section III.B). In HCV-229E, IBV, FIPV, and TGEV, the protein is N-glycosylated. Potential oligosaccharide attachment sites occur once in the relevant part of the HCV-229E M sequence (position 45 in Fig. 2), twice in the case of IBV M (positions 35 and 38), and once in the cases of FIPV and TGEV M (position 33). These sites are indeed used as the numbers of side chains are in agreement with those experimentally observed (Stern and Sefton, 1982b; Kapke et al., 1988; Vennema et al., 1991b). Another N-glycosylation consensus sequence (positions 58-60 in Fig. 2) occurs at the start of the first internal hydrophobic region of some $M$ proteins but appears not to be used. Apparently, this sequence is not exposed to the modifying enzymes in the endoplasmic reticulum and resides within the membrane.

It is not known which of the serine and threonine residues are substituted in the O-glycosylated coronavirus $M$ proteins. The structural features that determine a functional O-glycosylation site have not yet been established. In MHV, a cluster of four hydroxy amino acids is located next to the initiating methionine which presumably is removed posttranslationally as has been shown for IBV M (Cavanagh et al., 1986b). The resulting $\mathrm{NH}_{2}$-terminal tetrapeptide sequence (Ser-Ser-Thr-Thr) is identical to the O-glycosylated aminoterminus of glycophorin A, the major glycoprotein of the human erythrocyte membrane. It was shown by Niemann et al. (1984) that the O-linked sugar structures of MHV M are identical to those found in glycophorin. As the coronavirus protein also appeared to exhibit blood group $M$ activity, as does glycophorin, the authors inferred that the hydroxy amino acid cluster contains the functional oligosaccharide acceptor sites in MHV M. On the basis of the heterogeneity in the glycosylation of the M protein, they concluded that up to three of the four residues in the cluster are modified by oligosaccharide side chains. In BCV a slightly different cluster of hydroxy amino acids occurs at the $\mathrm{NH}_{2}$-terminus due to the presence of a valine residue (Fig. 2). Assuming that the sequence requirements for glycosylation allow for this difference, Lapps et al. (1987) suggested, by analogy, that the additions of the glycans take place in this terminal segment. They argued that, in the case of BCV, up to two O-linked oligosaccharide side chains per $\mathrm{M}$ molecule are attached.

Recent sequence information shows that considerable genetic diversity exists among different strains or isolates of coronaviruses in their spike protein (e.g., for MHV, see Luytjes et al., 1987; Schmidt et al., 1987; Parker et al., 1989; Gallagher et al., 1990; Wang et al., 1992). The limited data available for the M gene suggest that variations are less extensive. Comparison, for instance, of the A59 and JHM strains of MHV (Pfleiderer et al., 1986) revealed 21 nucleotide changes scattered over the entire molecule, which result in only seven conservative amino acid changes (3.5\%). Cavanagh and Davis (1988) analyzed the $\mathrm{NH}_{2}$-terminal domain, including the first hydrophobic region, of the $\mathrm{M}$ sequence of 23 strains of IBV. Both base substitutions and small deletions and insertions were detected. A fourfold greater extent of amino acid variation was found in the ectodomain of the protein as compared to the membrane-embedded segment. Notably, one of the $\mathrm{N}$-glycosylation sequences (positions 38-40 in Fig. 2) was highly conserved while the other (positions 35-37) was not. Also, based on a complete comparison of $M$ sequences of two IBV strains (Binns et al., 
1986), it was concluded that the exposed $\mathrm{NH}_{2}$-terminal domain is the most variable part of the molecule. The M proteins of TGEV and PCRV (Rasschaert $e t$ al., 1990), two closely related porcine coronaviruses, also differ in their amino acid sequences at 13 positions, 8 of which occur in the amino terminal part preceding the first hydrophobic region.

\section{B. Membrane Topology}

The disposition of the $\mathrm{M}$ molecule in the lipid bilayer was studied through protease protection analyses. Digestion of in vitro assembled MHV-A59 M protein showed the bulk of the polypeptide to be resistant to proteolysis: only a small $(1.5-\mathrm{kDa})$ portion was removed when the membranes were intact while another $2.5-\mathrm{kDa}$ fragment was digested after detergent permeabilization (Rottier et al., 1984). The latter fragment is located luminally and represents the $\mathrm{NH}_{2}$-terminus of the molecule, as was shown by selective labeling. In virions, this $2.5-\mathrm{kDa}$ fragment is exposed on the outside and is glycosylated to a variable extent, while the $1.5 \mathrm{kDa} \mathrm{COOH}$-terminal end protrudes from the inner face of the membrane. Experiments with IBV (Cavanagh et al., 1986a) suggest that the tertiary structure of the $\mathrm{M}$ protein of this virus, and probably of other coronaviruses as well, is very similar.

The results of the biochemical studies, combined with a theoretical analysis of the primary structure of the M polypeptide, have led to a general topological model of the assembled protein as shown in Fig. 4A (Armstrong et al., 1984; Rottier et al., 1986). The structure is characterized by the presence of three membrane-spanning helices in the $\mathrm{NH}_{2}$-terminal half that anchor the protein in the lipid bilayer. This segment is flanked on the one side by the hydrophilic $\mathrm{NH}_{2}$-terminus and on the other side by a region that contains the extremely well-conserved 8 amino acids domain (Fig. 2) and in which a surface helix is predicted for some (but not all) M proteins (Rottier et al., 1986). The bulk of the carboxy-terminal half of the $\mathrm{M}$ molecule is supposedly embedded in the polar surface of the membrane. In line with this, a mutant $M$ protein lacking all the

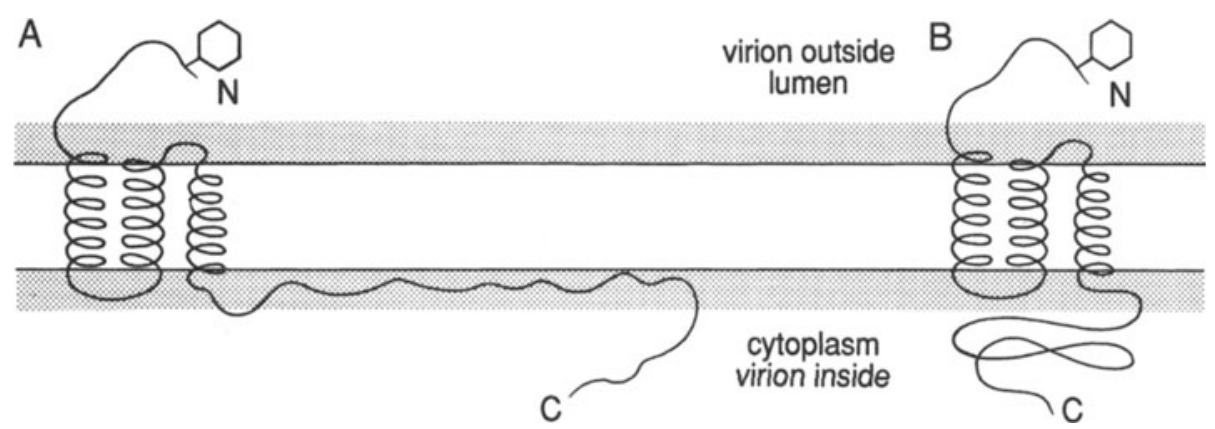

FIGURE 4. Topological models of the membrane-assembled $M$ protein. Note that the two models differ only in the disposition of the protease-resistant region in the carboxy-terminal half. The hexagon symbol attached to the $\mathrm{NH}_{2}$-terminal region indicates the potential glycosylation sites. 
membrane-spanning domains was found to associate with membranes in vitro (Mayer et al., 1988). However, a location of this extremely protease resistant region adjacent to the membrane, as in Fig. 4B, cannot be excluded.

\section{ASSEMBLY IN THE ENDOPLASMIC RETICULUM}

Viral proteins use mechanisms and intracellular pathways as do normal cellular proteins. The process by which a nascent polypeptide is directed to and assembled in the endoplasmic reticulum occurs quite rapidly. Therefore, these processes are most conveniently studied in in vitro systems, which are easier to manipulate and in which the reaction kinetics are inherently slower. Though these systems have given us insight into the processes involved in the insertion and translocation of simple membrane and secretory proteins, little is known about the events that generate the more complex, multispanning membrane proteins. The coronavirus $M$ protein, relatively simple as it is with only three transmembrane domains, thus represents an attractive model.

The MHV-A59 M protein is translated on membrane-associated polysomes (Niemann et al., 1982). Its membrane insertion involves the action of the ribonucleoprotein complex called the signal-recognition particle (SRP). In a wheat germ translation system devoid of membranes, the synthesis of the protein could be specifically and stably blocked by the addition of SRP. Subsequent addition of salt-washed microsomes fully released the translation arrest and resulted in the correct membrane integration of the polypeptide (Rottier $e t$ al., 1985).

In agreement with the absence of a hydrophobic $\mathrm{NH}_{2}$-terminal peptide, the protein is assembled without a cleavable signal sequence (Rottier et al., 1984). The polypeptide chain is inserted into the lipid bilayer in a cotranslational manner. Time course experiments in a synchronized in vitro translation of the $M$ mRNA showed that the nascent polypeptide chain was able to integrate when membranes were added before 140-150 of the 228 residues had been polymerized. Later additions no longer allowed membrane insertion. Once beyond a critical point in synthesis, the domain containing the insertion signal(s) is apparently no longer accessible to the insertion machinery. Additional time course experiments revealed that such signal(s) may be located anywhere within the hydrophobic $\mathrm{NH}_{2}$-terminal half of the molecule. During a synchronized translation in a wheat germ extract, SRP was able to induce an arrest until the most $\mathrm{C}$-terminal hydrophobic domain had emerged from the ribosome (Rottier et al., 1985).

Direct evidence that the topogenic signals in the $M$ protein reside within the hydrophobic part of the polypeptide came from expression studies with cloned cDNA copies of $M$ genes. In vitro mutagenesis followed by transcription and translation in the presence of microsomal membranes showed that each hydrophobic domain can individually insert and anchor the polypeptide in the membrane (Mayer et al., 1988; Rottier et al., 1990; Krijnse Locker et al., 1992b). Similar results were obtained by expression of mutant M genes of MHV-A59 M (Mayer et al., 1988; Armstrong et al., 1990; Krijnse Locker et al., 1992b) and IBV 
M (Machamer and Rose, 1987). The mutant proteins with only the first or the third transmembrane domain integrate in membranes such that their $\mathrm{NH}_{2}$ terminus is translocated into the lumen, while their $\mathrm{COOH}$-terminus remains on the cytoplasmic side. Large deletions in the hydrophilic $\mathrm{NH}_{2}$-terminal region did not affect this ability, nor did the mutations alter the topology of the assembled protein (Mayer et al., 1988; Krijnse Locker et al., 1992b). This part of the protein consequently plays no role in the membrane integration process. As expected, similar conclusions could be drawn from studies of mutations in the carboxy-terminal domain (Armstrong et al., 1990; Rottier et al., 1990; Krijnse Locker et al., 1992b).

These observations lead to the model shown in Fig. 5. SRP interacts with the first hydrophobic domain as soon as it appears from the ribosome; elongation halts until the complex has attached to the membrane where the hydrophobic domain interacts with the signal sequence receptor and is inserted into the membrane, probably as a hairpin, while SRP is released. Presumably, the hydrophilic $\mathrm{NH}_{2}$-terminus is translocated and the two following hydrophobic domains are then sequentially inserted. Completion of the polypeptide chain accompanied by further cotranslational folding finally leads to the fully assembled protein.

Interestingly, the deduced amino acid sequences of the TGEV (Laude et al., 1987; Kapke et al., 1988), FIPV (Vennema et al., 1991a), and canine coronavirus (CCV) M protein (Horsburgh et al., 1992) have a hydrophobic amino terminal extension (see Section III.A). Sequencing of the mature $M$ polypeptide from purified TGEV showed that the first 17 residues were absent, indicating a cleavable signal sequence (Laude et al., 1987). Translation studies with mRNA specifying TGEV $M$ showed the signal-directed membrane insertion of the protein in vitro, although cleavage did not occur under these conditions (Kapke et al., 1988). These authors also tested the expression of a truncated version of

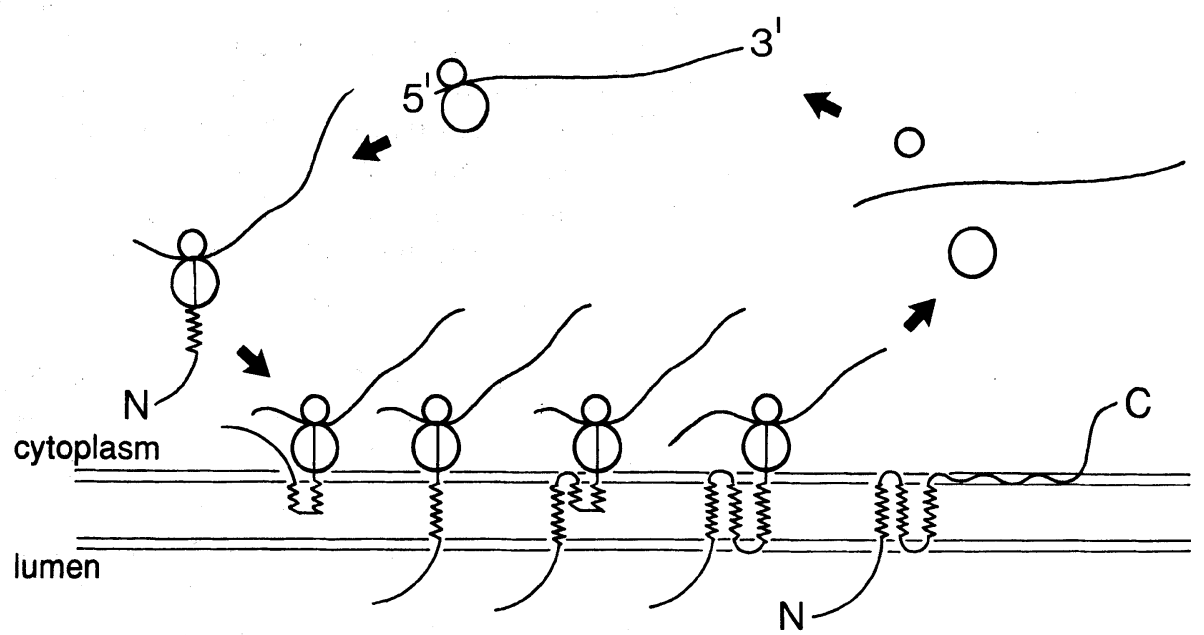

FIGURE 5. Model of the membrane assembly process of the coronavirus M protein. 
the gene which lacked the information for the signal-containing first 21 residues. Though the polypeptide appeared to be integrated efficiently into microsomal membranes, translocation of the $\mathrm{NH}_{2}$-terminal domain was poor, as judged from the small extent of $\mathrm{N}$-glycosylation of the protein. In contrast, deletion of the signal sequence had no effect when the FIPV $M$ protein was expressed in a vaccinia virus/cell system (Vennema et al., 1991b). The mutant protein was glycosylated as efficiently as the wild-type protein. Why, in these viruses, the $M$ protein contains a cleavable amino-terminal signal sequence thus remains unclear.

\section{INTRACELLULAR TRANSPORT AND MATURATION}

\section{A. Transport and Processing in Coronavirus-Infected Cells}

Intracellular transport of the coronavirus $M$ protein differs from that of most other viral glycoproteins, including the coronaviral spike protein. Whereas these proteins are usually targeted to the cell surface, migration of the $M$ protein is limited to the perinuclear region of the cell. This restricted mobility correlates with the intracellular location of coronavirus assembly in the infected cell.

\section{Intracellular Budding of Coronaviruses}

Already from the early studies of the coronavirus infection process, it became clear that the entire replication cycle takes place in the cytoplasm. Ultrastructural observations with different coronaviruses demonstrated that morphogenesis occurs at intracellular membrane-bound compartments as virions were seen in the lumina of the rough endoplasmic reticulum, smoothwalled vesicles and Golgi apparatus (e.g., David-Ferreira and Manaker, 1965; Becker et al., 1967; Chasey and Alexander, 1976; Holmes and Behnke, 1981; Dubois-Dalcq et al., 1982, 1984). Virus budding never takes place at the plasma membrane. A thorough investigation by J. and S. A. Tooze et al. (J. Tooze et al., 1984, 1985, 1987; S. A. Tooze et al., 1988), using a combination of biochemical and morphological techniques, has elucidated the temporal sequence of events in the maturation of MHV-A59 in Sac|-| cells, a line of transformed murine fibroblasts. Early in infection, shortly after the appearance of $M$ and $S$, the first progeny virions are seen by electron microscopy in the perinuclear region. Budding of these early particles occurs into small, smooth vesicles or tubules lying between the rough endoplasmic reticulum and the cis side of the Golgi stack. This smooth membrane compartment, termed budding compartment by the authors (S. A. Tooze et al., 1988), is distinct from and does not form part of the Golgi complex but is connected to the rough endoplasmic reticulum (Krijnse Locker et al., 1994a). At early times, budding does not occur in either of these two organelles. Later, however, budding also starts to occur into the rough membranes of the endoplasmic reticulum, and this compartment becomes the major site of virus assembly late in infection. Budding into the Golgi cisternae 
is a rare event. Virions are transported from their site of synthesis to and through the Golgi complex by vesicular carriers. In the Golgi complex they are usually seen only at the rims of the stacks. At the trans side of the Golgi system, particles are collected into vesicles of the constitutive exocytic pathway (J. Tooze et al., 1987) and released from the cell.

The budding compartment also exists in uninfected Sac(-) cells, where it is associated with transitional elements and vesicles of the rough endoplasmic reticulum and the cis side of the Golgi complex. Presumably, it is equivalent to the intermediate or salvage compartment which plays a crucial role in the sorting of resident proteins of the endoplasmic reticulum (for review, see Hauri and Schweizer, 1992). As virions accumulate in the budding compartment during MHV-A59 infection, it becomes strongly dilated.

Budding into the intermediate compartment seems to be a general feature of coronaviruses. An ultrastructural analysis of cells infected with IBV, TGEV, or FIPV revealed that these viruses also use the smooth perinuclear membranes (Klumperman et al., 1994). Budding into such tubulovesicular membrane structures has also been described in neural cells infected with either MHV-A59 or the JHM strain of MHV (Dubois-Dalcq et al., 1982).

\section{Localization and Transport of the M Protein}

After its synthesis on membrane-bound polyribosomes, the M protein is transported from the endoplasmic reticulum and through the Golgi complex to finally appear outside the cell as part of virions. The rate and extent of this process differs depending on the particular virus-cell system and on the time of infection. Pulse-chase experiments early in MHV-A59 infection showed the M protein to be chased almost quantitatively from $17 \mathrm{Cll}$ cells within about $2 \mathrm{hr}$ (Holmes et al., 1981a). In contrast, very inefficient clearance of $M$ was observed, both from 17C11 cells (Holmes et al., 1981b) and from Sac/-) cells (Rottier et al., 1981b) during a similar period somewhat later in the infection cycle. It appears that in early stages the synthesis of the protein is balanced with its release in virions.

To relate the localization of the MHV-A59 M protein to the site of budding, J. and S. A. Tooze et al. (J. Tooze et al., 1984; S. A. Tooze et al., 1988) labeled infected Sac| - | cells for indirect immunofluorescence with a monoclonal antibody to the protein. Early in infection, a perinuclear fluorescence pattern was observed that was similar to but more extensive than that obtained with antibodies specific for the Golgi apparatus. As infection proceeded, a more reticular staining throughout the cell appeared. No labeling of the plasma membrane occurred until late in infection when patches of fluorescence indicated association of released virions with the cell surface. Immunoperoxidase staining confirmed that the $M$ protein had accumulated in the budding compartment and not in the endoplasmic reticulum early in infection. There was, however, also some labeling of the stacked cisternal membranes of the Golgi complex, indicating that some $M$ protein reaches the Golgi apparatus as free integral membrane protein. As no virus assembly is observed in these compartments, it was 
inferred that the density of the protein in this organelle apparently does not reach the critical threshold level required for budding.

Similar data were obtained by Klumperman et al. (1994) in a study of the subcellular localization of $M$ proteins in coronavirus-infected cells. Using immunogold labeling and electron microscopy, they demonstrated that in MHV and IBV infection, both in Sacl-) cells, free $M$ protein is present in the membranes of the budding compartment as well as in the Golgi complex. Within the Golgi complex, the distribution patterns of MHV-M and IBV-M were found to be different. MHV-M was localized more toward the trans side, while IBV-M was concentrated on the cis side, similar to the patterns found when these proteins are expressed independently (Machamer et al., 1990; Krijnse Locker et al., 1992a; Klumperman et al., 1994).

The combined data indicate that at early times the $M$ protein is transported as an integral membrane protein to the smooth membranes of the budding compartment where it accumulates and is incorporated into virions and from where it is exported through the Golgi complex out of the cell. At later times, when the rate of $M$ synthesis in the rough endoplasmic reticulum exceeds the rate of its exit to the budding compartment, the protein allows virion assembly also in these reticular membranes. A fraction of $M$ apparently escapes from being incorporated into virions and accumulates in the Golgi complex.

Interestingly, when the temperature of Sacl- - cells infected with MHVA59 was lowered to $31^{\circ} \mathrm{C}$, release of virions was strongly inhibited (S. A. Tooze et al., 1988). Electron microscopic analysis showed that virion formation at this temperature occurred normally, but that the particles accumulated in the budding compartment and in the rough endoplasmic reticulum. Entry of virions into the Golgi complex appears to be inhibited at $31^{\circ} \mathrm{C}$, as few virions were observed in or beyond this compartment and the $M$ protein did not undergo the oligosaccharide modifications known to occur there.

MHV M protein is not transported as free integral membrane protein to the plasma membrane of infected cells (Dubois-Dalcq et al., 1982; J. Tooze et al., 1984,1987 ; S. A. Tooze et al., 1988; S. A. Tooze and Stanley, 1986). The protein is detected there only in extracellular virions that have readsorbed in clusters to the cell surface (Sugiyama and Amano, 1981; Dubois-Dalcq et a1., 1982; S. A. Tooze et al., 1988). This is in keeping with the Golgi localization of MHV-M when expressed from its cloned gene (see Section VB). It was surprising, therefore, that free $M$ protein was observed at the surface of cells infected with TGEV. This was shown both biochemically (surface iodination) and serologically using M-specific monoclonal antibodies by Laviada et al. (1990). The protein was detected at the plasma membrane as early as $4 \mathrm{hr}$ after infection, i.e., before any infectious virus had been released from the cells. In another study, however, Pulford and Britton (1990) could not confirm these findings.

\section{Oligosaccharide Modifications during Transport}

Transport of glycoproteins through the biosynthetic pathway of the cell is accompanied by modifications of their glycan moieties as they encounter the 
modifying enzymes. Due to the specific locations of these enzymes, the modifications occur sequentially in time and place. As a consequence, the state of glycosylation is an indicator of a glycoprotein's progress on the exocytic route. Many of the oligosaccharide-processing enzymes occur in the Golgi apparatus. The formation of coronavirions in a pre-Golgi compartment thus implies that these enzymes act on glycoprotein molecules which present themselves as parts of huge macromolecular structures.

The $M$ protein of a number of coronaviruses is glycosylated only by O-linked carbohydrates (see Table I). This type of linkage is rare among viral glycoproteins, but is found quite frequently in various cellular glycoproteins. Usually, O-linked oligosaccharides occur on a polypeptide in combination with $\mathrm{N}$-glycosidically linked side chains. Sometimes the O-glycosylation pattern is very extensive and complex such as in mucin-type molecules. For these and other reasons, O-glycosylation has been difficult to study, and our knowledge lags far behind that of $\mathrm{N}$-glycosylation. Because of its relative simplicity, the coronavirus $\mathrm{M}$ protein seems an attractive tool to catch up.

The M protein of MHV-A59 has been resolved into a number of differentially O-glysosylated forms. As mentioned previously, two types of oligosaccharide side chains are bound to $\mathrm{M}$ in the virions produced by $17 \mathrm{Cll}$ cells (see Fig. 1) (Niemann et al., 1984). The same structures were found to predominate when the virus was grown in Sac(-) cells (S. A. Tooze et al., 1988), but at least two additional glycosylated species were detected in these cells. One was identified as carrying only $\mathrm{N}$-acetyl-galactosamine (GalNAc); the other was not identified. Two glycosylated forms were observed in AtT20 cells, a pituitary tumor cell line, but their structures were not clearly resolved (J. Tooze et al., 1987). In all cases, a significant proportion of the M molecules remained unglycosylated. These observations indicate that the extent and possibly also the nature of O-glycosylation varies and is determined by the host cell.

Early studies on the biosynthesis of MHV-A59 M, both in infected Sacl-1 cells (Rottier et al., 1981b) and in 17C11 cells (Holmes et al., 1981b; Niemann et al., 1982), suggested that the addition of O-linked oligosaccharides is a posttranslational event. This idea is now well established (S. A. Tooze et al., 1988; Krijnse Locker et al., 1992a, 1994a). The M protein is synthesized in a nonglycosylated form in the rough endoplasmic reticulum and is transported to the intermediate compartment where the first sugar, GalNAc, is added. Due to the membrane-continuities between these compartments, no vesicular transport step is required for this addition (Krijnse Locker et al., 1994a). All subsequent modifications occur in the Golgi apparatus. First, a galactose unit is added, followed immediately by sialic acid. The transferase enzymes responsible for these additions are both located in Golgi cisternae, proximal to the trans-Golgi network. Finally, further modifications can lead to the appearance of two more forms of the $M$ protein, the oligosaccharides of which have not been characterized. These modifications occur in the trans-Golgi network as they can be inhibited specifically by treatment of the cells with the drug brefeldin A (Krijnse Locker et al., 1992a).

Coronavirus $\mathrm{M}$ proteins that are modified by $\mathrm{N}$-linked oligosaccharides acquire their sugars cotranslationally in the endoplasmic reticulum. Core- 
glycosylation is, however, not a very efficient process with these proteins. Unglycosylated and partially glycosylated molecules occur in infected cells as well as in the virions released from them (Stern and Sefton, 1982a, b; Stern et al., 1982; Cavanagh, 1981, 1983; Vennema et al., 1990b; Jacobs et al., 1986). Incomplete glycosylation does not correlate with the involvement of a cleavable $\mathrm{NH}_{2}$ terminal signal sequence during biosynthesis; it was observed both with IBV and with FIPV and TGEV $M$ proteins which have an internal and an amino terminal insertion signal, respectively. During transport to the budding compartment, and on passing through the Golgi complex en route to the plasma membrane, the high-mannose oligosaccharides are trimmed and processed, having been converted to the complex type as they are released from the cell. Again, these processes occur very inefficiently, since a significant proportion of the $M$ molecules in extracellular virions remains sensitive to the enzyme endoglycosydase $\mathrm{H}$ which only recognizes immature glycans (Stern and Sefton, 1982b; Cavanagh, 1983; Vennema et al., 1990b). The incomplete maturation of coronavirus glycoproteins is not specific for the $M$ protein. The same applies to the S protein (Stern and Sefton, 1982b; Cavanagh, 1983; Vennema et al.,1990b). The reasons for these findings are unclear, but it is plausible that they are caused by steric effects. Since the proteins move through the Golgi compartments as part of and protruding from the viral envelope, access of the modifying enzymes to the oligosaccharides might well be severely hindered. Incomplete maturation of N-linked carbohydrates is not unprecedented and has occasionally been observed with other glycoproteins (Doyle et al., 1986; Geyer et al., 1988; Earl et al., 1991).

\section{B. Transport of the Expressed M Protein}

The interesting membrane structure and the intracellular restriction in coronavirus-infected cells prompted studies of the biogenesis and transport of the $M$ protein in the absence of other coronaviral proteins. The $M$ proteins of MHV-A59, IBV, TGEV, and FIPV have been expressed in cells from cloned cDNA (e.g., Machamer and Rose, 1987; Rottier and Rose, 1987; Machamer et al., 1990; Klumperman et al., 1994) as well as by microinjection of an in vitro transcribed mRNA (Armstrong et al., 1987, 1990; Mayer et al., 1988). These studies unequivocally demonstrate that the protein accumulates in the Golgi apparatus and does not reach the plasma membrane. Analysis of the expressed MHV-A59 M protein by immunofluorescence in various cell types revealed the perinuclear appearance typical for the Golgi complex (Armstrong et al., 1987; Rottier and Rose, 1987; Mayer et al., 1988; Krijnse Locker et al., 1992a; Klumperman et al., 1994 (see also Fig. 6). This localization was confirmed by electron microscopy using immunogold labeling and Golgi-specific markers (Krijnse Locker et al., 1992a; Klumperman et al., 1994), showing that within the Golgi complex the MHV M protein is concentrated in the trans-most compartments. Consistently, biochemical labeling revealed that, although a proportion of the molecules usually remained unglycosylated, as in coronavirus-infected cells, the large majority acquired the O-linked oligosaccharides added in the Golgi 


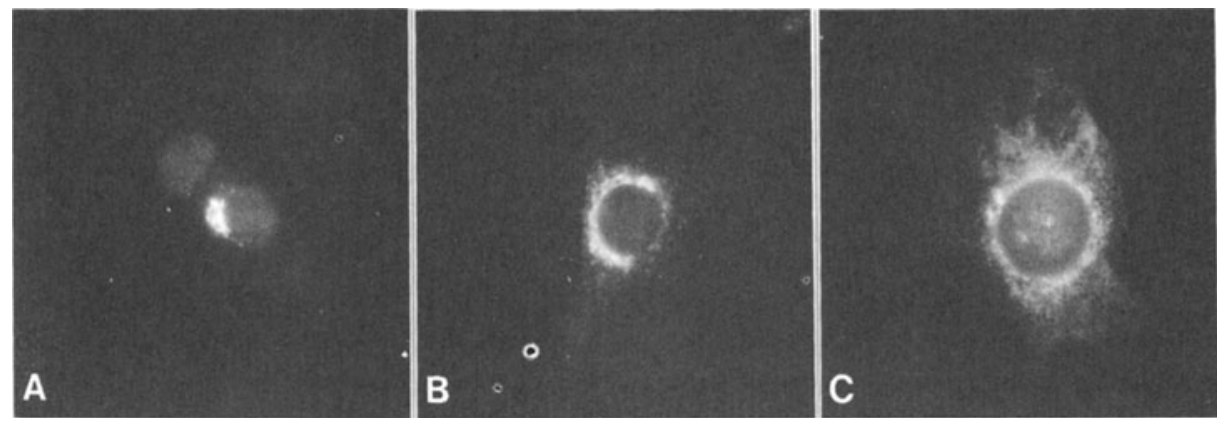

FIGURE 6. Localization of the MHV-A59 $M$ and $S$ protein by indirect immunofluorescence. Sacl-1 cells expressing the $M$ protein from $(A)$ a vaccinia virus vector or, $(B, C)$ during infection with $M H V$ A59 were stained with a M-specific antipeptide serum (A, B) or an S-specific monoclonal antibody after permeabilization.

apparatus (Armstrong et al., 1987; Rottier and Rose, 1987; Krijnse Locker et al., 1992a; Klumperman et al., 1994). In contrast, the IBV M protein expressed in AtT20 cells (Machamer et al., 1990) or in HepG2 cells (Klumperman et al., 1994) was localized by immunoelectron microscopy to the cis side of the Golgi complex. Accordingly, its $\mathrm{N}$-linked sugars remain largely immature. Taken together, these studies indicate that the intracellular restriction of coronavirus $\mathrm{M}$ is an intrinsic property of the protein and is not dependent on other coronaviral factors.

Its accumulation in the Golgi apparatus, midway on the exocytic pathway, has made the $M$ protein an attractive tool for studying the principles of targeting to and retention in this organelle. For the IBV protein, Machamer and coworkers (Machamer and Rose, 1987; Machamer et al., 1990, 1993; Swift and Machamer, 1991) have shown that the first transmembrane domain carries the signal necessary and sufficient for localization in the cis-Golgi region. This was demonstrated most convincingly by transferring the hydrophobic domain into reporter molecules normally transported to the plasma membrane and showing their Golgi retention (Swift and Machamer, 1991). Several uncharged polar residues were found to be critical for the functioning of the domain. These residues line one face of a predicted $\alpha$-helix formed by the transmembrane domain (Swift and Machamer, 1991; Machamer et al., 1993). Surprisingly, no such role is played by the first transmembrane domain of the MHV M protein. A mutant $M$ protein with only this transmembrane domain did not leave the endoplasmic reticulum (Armstrong et al., 1990; Rottier et al., 1990), although inserting this domain in place of the membrane-spanning domain of a plasma membrane protein still allowed this chimeric molecule to reach the cell surface (Machamer et al., 1993). Mutation studies with the MHV M protein indicate that, in this case, the carboxy-terminal domain, probably in combination with an internal domain, determines the Golgi localization (Armstrong and Patel, 1991; Krijnse Locker et al., 1994b). It was suggested that different principles may act in the differential localization of the IBV and MHV M proteins in the Golgi complex (Weisz et al., 1993). 


\section{BIOLOGICAL FUNCTIONS}

Glycoproteins of enveloped viruses are involved in a number of biological activities. Envelope proteins function in the binding of virions to cell receptors. They mediate the introduction of the nucleocapsid into the cytoplasm by triggering the fusion of viral and cellular membranes. Viral membrane proteins are also essential at the end of the infection cycle during the process of virion assembly. In some viruses, envelope glycoproteins exhibit receptor-destroying activities. Finally, the proteins generally induce immunological responses in the host by eliciting neutralizing antibodies and cytotoxicity. In coronaviruses, several of these properties have been attributed to the $S$ and HE proteins. The $M$ protein has been demonstrated to play a key role in coronavirus budding and to induce immunological reactions during infection in the host.

\section{A. Role of $\mathrm{M}$ in Coronavirus Budding}

There are two types of findings pointing to a predominant function of the $M$ protein in the intracellular formation of progeny virus particles. First, growth of coronaviruses in the presence of tunicamycin gave rise to the production of spikeless, noninfectious virions (Holmes et al., 1981b; Rottier et al., 1981b; Stern and Sefton, 1982b; Mounir and Talbot, 1992). These particles were indeed devoid of $S$ and $H E$ protein but contained $M$, suggesting that $M$ is the only envelope glycoprotein required for virus budding. Second, throughout the infection there is a correlation between the intracellular sites at which progeny virions bud and the perinuclear location of the $M$ protein (see Section V). Concentration and location of $M$ apparently are decisive in determining where and when budding occurs.

Molecular details of the budding process have not yet been elucidated. Conceivably, the $M$ protein is transported as an integral membrane protein to the budding compartment or, later in infection, backs up in the endoplasmic reticulum. The protein accumulates locally to a concentration high enough to be recognized by nucleocapsids formed in the cytosol. The nucleocapsids associate with the $M$ protein by interacting with its cytoplasmic domain. These interactions initiate budding into the lumen of the membrane compartment, whereby $M$ is sequestered into progeny virions. An affinity of $M$ for nucleocapsids has been observed in vitro with several coronaviruses. Subviral particles prepared by Nonidet P-40 disruption of purified MHV (Wege et al., 1979; Sturman et al., 1980), HEV (Callebaut and Pensaert, 1980), IBV (Lanser and Howard, 1980), or BCV (King and Brian, 1982) still contained M protein associated with the nucleocapsids. The significance of these interactions remains to be assessed. Binding of MHV-M to nucleocapsids did occur through an interaction with the RNA but was not specific for viral RNA and was dependent on a temperature-induced conformational change in the M protein (Sturman et al., 1980). The distribution of positive charges over the M molecule certainly seems to favor an association with the viral RNA. For instance, all but one of the 18 arginines and lysines present in the MHV M protein are located at the cyto- 
plasmic face of the intracellular membrane; of these, 5 occur in the carboxyterminal 24 amino acids.

Little is still known about where and how the other viral membrane proteins are assembled into coronavirions. Electron microscopic observations have shown that the envelopes of budding virions were covered with peplomers (Chasey and Alexander, 1976; Dubois-Dalcq et al., 1982). Apparently, budding involves the collective incorporation of all viral envelope proteins. This implies that the spike glycoproteins convene with the M proteins at the sites of budding and, by consequence, that the different viral envelope proteins recognize each other and interact. Association of the M and S protein in MHV-A59 infected cells has indeed been demonstrated (Opstelten et al., 1993a, 1994). After their synthesis, $\mathrm{M}$ molecules rapidly engage in formation of noncovalently linked heteromultimeric structures with $\mathrm{S}$ proteins, probably already in the endoplasmic reticulum. In contrast, newly synthesized S protein first has to undergo a number of folding reactions before it reaches a conformation competent to interact with $M$. If proper folding of $S$ is prevented, e.g., by inhibiting the formation of disulfide bonds, no complexes between the two proteins are formed and the M protein is transported to the Golgi complex (Opstelten et al., 1993b).

These data suggest a model of virus assembly in which the viral envelope proteins form complexes that accumulate in the budding compartment to generate a microenvironment where nucleocapsids can bind and assemble into virions. Such a process would explain the exclusion of host cellular membrane proteins from virions as the molecular selection for viral membrane proteins would preclude their incorporation into the heteromultimeric complexes. It might also explain why the $M$ and $S$ proteins are efficiently assembled into viral particles in the budding compartment, while their intrinsically preferred destinations are the Golgi complex and the plasma membrane, respectively. Consistent with such a model, the MHV M and S proteins when coexpressed in cells were found to associate and form complexes (D.-J. Opstelten and P. Rottier, unpublished observations). Surprisingly, however, these complexes were not retained in the budding compartment, but accumulated in the Golgi complex. Apparently, other viral factors are required to localize budding in pre-Golgi membranes. One possibility is that the nucleocapsid plays an organizing role. Alternatively, the small nonglycosylated virion membrane protein (SM) might be important. So far, this protein has largely been neglected. Further studies are warranted, however, because the protein was recently shown to play a key role in the formation of viruslike particles (H. Vennema, G.-J. Godeke, and P. Rottier, unpublished observations).

While the M protein is required for budding, its glycosylation is not. Nonglycosylated coronavirus $\mathrm{M}$ proteins are able to efficiently direct the formation of virions as was shown using tunicamycin (Stern and Sefton, 1982b) and monensin (Niemann et al., 1982), inhibitors of N- and O-glycosylation, respectively. Moreover, in the absence of drugs no particular form of the differentially glycosylated $\mathrm{M}$ species is preferentially incorporated into virions. Their relative abundance in extracellular viral particles correlates with the ratio of their 
appearance in the infected cell (Stern and Sefton, 1982b; Holmes et al., 1981a). Additional evidence that glycosylation of $M$ is not essential for virus assembly comes from the demonstration by Laude et al. (1992) that disruption of the consensus sequence of the sole $\mathrm{N}$-glycosylation site in the M protein of TGEV results in a viable mutant virus. The authors mention that the mutation did not affect the specific infectivity of the virus nor its multiplication rate. Apparently, the oligosaccharides attached to the coronaviral $M$ proteins are not important for the infection process at the level of the cell. They probably play a role in the interaction with the host at the level of the organism.

\section{B. Induction of Immunological Responses}

With the exception of FIPV (Vennema et al., 1990a), the S glycoprotein of coronaviruses is believed to be the prime inducer of protective immunity. Nevertheless, several observations indicate that immune responses to other viral proteins, including the $M$ protein, may also play a role. Though largely buried within the membrane, the $M$ protein does elicit specific antibodies during infection in the host and also when expressed separately through a live carrier virus (e.g., Pulford and Britton, 1990; Vennema et al., 1991a; Wesseling et al., 1993).

Monoclonal antibodies to the $M$ protein can neutralize infectivity in vitro, but only in the presence of complement, as was shown for some monoclonal antibodies to MHV-M (Collins et al., 1982; Fleming et al., 1989) and TGEV-M (Woods et al., 1988). In most cases, however, anti-M antibodies appear nonneutralizing in vitro (Buchmeier et al., 1984; Laude et al., 1986; Deregt and Babiuk, 1987; Fiscus and Teramoto, 1987; Fleming et al., 1989).

Little is known about the protective effects of antibodies to the $M$ protein in animals. Monovalent antibodies elicited by immunization of mice with purified MHV M protein failed to protect against a virus challenge (Hasony and Macnaughton, 1981). In contrast, two of four monoclonal antibodies to MHVJHM M did protect mice from a normally lethal challenge after passive transfer (Fleming et al., 1989). This protection was not associated with a particular antigenic determinant in the $M$ protein nor was it mediated by complement. Interestingly, one of the two antibodies was not neutralizing in vitro, not even in the presence of complement. Some level of protection against another coronavirus was also observed in cats after immunization with a recombinant vaccinia virus expressing the FIPV M protein (Vennema et al., 1991a). Although all animals seroconverted after a challenge with a lethal dose of FIPV and developed clinical signs, three of eight kittens survived.

The $M$ protein of TGEV can induce the production of $\alpha$-interferon in lymphocytes as was shown by the inhibiting effect of anti-M monoclonal antibodies on interferon induction by fixed TGEV-infected cells /Charley and Laude, 1988). By analysis of mutant viruses with reduced interferogenic potential, this biological activity was mapped to the exposed amino-terminal region 
of the M molecule (Laude et al., 1992). The significance of $\alpha$-interferon action for immunity to viral infection needs to be established.

Little is known about the cellular immune response to coronavirus infections. A cytotoxic $\mathrm{T}$-cell response to the $\mathrm{M}$ protein has not been described. It has been suggested, however, that cell-mediated recognition of the M protein might be an important part of an effective immune response to MHV-JHM (Mobley et al., 1992).

\section{SUMMARY AND PERSPECTIVES}

The coronavirus M protein has a unique molecular structure. The different domains in its structure may explain the specific properties of the protein and reflect its biological features in infection.

The $\mathrm{N}$-terminal hydrophilic virion ectodomain carries the $\mathrm{N}$ - or O-linked oligosaccharides. It is the most variable part of the molecule which presumably contains the major antigenic determinants. It is responsible for immunological reactions such as antibody and interferon induction.

The hydrophobic region containing the three transmembrane helixes constitutes the core of the protein and is probably responsible for its peculiar physical properties. This region dictates the protein's topology in the membrane and its intracellular transport. It is the part of the protein most likely to be engaged in the intermolecular interactions that must occur at the membrane during the virion assembly process, both mutually between $\mathrm{M}$ molecules and with other viral membrane proteins.

The carboxy-terminal half of the molecule consists of an amphiphilic portion and an exposed tail facing the cytoplasm in infected cells. Virion budding is accomplished by the association of nucleocapsids with this part of the $M$ protein.

The data reviewed in this chapter demonstrate that the coronavirus $M$ protein has a number of interesting features both as a virion protein and as a model membrane protein. Though much has already been learned, many fundamental questions remain to be answered. Clearly, more needs to be known about the precise mechanism by which the protein is assembled in the membrane, about the disposition of the amphiphilic region of the molecule, and about the signals governing its intracellular transport. Little is known about the molecular details of the assembly of coronaviruses, the interactions of the $M$ proteins with the nucleocapsid, or the interactions with the other membrane components. Nothing is known about the importance of the differential glycosylation among coronaviral $M$ proteins. Some of these questions may be approached through mutagenesis and expression of the $M$ gene. The answer to most questions, however, will require the generation of mutant viral genomes, either by the manipulation of infectious cDNA clones or by RNA recombination. This holds true not only with respect to the role of the $M$ protein but for the molecular analysis of coronavirus infection in general. Evidently, this will be the major challenge for coronavirologists in the years to come. 


\section{REFERENCES}

Armstrong, J., and Patel, S., 1991, The Golgi sorting domain of coronavirus E1 protein, J. Cell Sci. 98:567.

Armstrong, J., Niemann, H., Smeekens, S., Rottier, P., and Warren, G., 1984, Sequence and topology of a model intracellular membrane protein, El glycoprotein, from a coronavirus, Nature 308: 751 .

Armstrong, J., McCrae, M., and Colman, A., 1987, Expression of coronavirus E1 and rotavirus VP10 membrane proteins from synthetic RNA, J. Cell. Biochem. 35:129.

Armstrong, J., Patel, S., and Riddle, P., 1990, Lysosomal sorting mutants of coronavirus El protein, a Golgi membrane protein, J. Cell Sci. 95:191.

Becker, W. B., McIntosh, K., Dees, J. H., and Chanock, R. M., 1967, Morphogenesis of avian infectious bronchitis virus and a related human virus (strain 229E), J. Virol.. 1:1019.

Binns, M. M., Boursnell, M. E. G., Tomley, F. M., and Brown, T. D. K., 1986, Nucleotide sequence encoding the membrane protein of the IBV strain 6/82, Nucleic Acids Res. 14:5558.

Boursnell, M. E. G., Brown, T. D. K., and Binns, M. M., 1984, Sequence of the membrane protein gene from avian coronavirus IBV, Virus Res. 1:303.

Bradburne, A. F., 1970, Antigenic relationships amongst coronaviruses, Arch. Gesamte Virusforsch. 31:352.

Buchmeier, M. J., Lewicki, H. A., Talbot, P. J., and Knobler, R. L., 1984, Murine hepatitis virus-4 (strain JHM)-induced neurologic disease is modulated in vivo by monoclonal antibody, Virology 132:261.

Callebaut, P. E., and Pensaert, M. B., 1980, Characterization and isolation of structural polypeptides in haemagglutinating encephalomyelitis virus, J. Gen. Virol. 48:193.

Cavanagh, D., 1981, Structural polypeptides of coronavirus IBV, J. Gen. Virol. 53:93.

Cavanagh, D., 1983, Coronavirus IBV glycopolypeptides: Size of their polypeptide moieties and nature of their oligosaccharides, I. Gen. Virol. 64:1187.

Cavanagh, D., and Davis, P. J., 1988. Evolution of avian coronavirus IBV: Sequence of the matrix glycoprotein gene and intergenic region of several serotypes, J. Gen. Virol. 69:621.

Cavanagh, D., Davis, P. J., and Pappin, D. J. C., 1986a, Coronavirus IBV glycopolypeptides: Locational studies using proteases and saponin, a membrane permeabilizer, Virus Res. 4:145.

Cavanagh, D., Davis, P. J., Pappin, D. J. C., Binns, M. M., Boursnell, M. E. G., and Brown, T. D. K., 1986b, Coronavirus IBV: Partial amino terminal sequencing of spike polypeptide S2 identifies the sequence Arg-Arg-Phe-Arg-Arg at the cleavage site of the spike precursor propolypeptide of IBV strains Beaudette and M41, Virus Res. 4:133.

Charley, B., and Laude, H., 1988, Induction of alpha interferon by transmissible gastroenteritis coronavirus: Role of transmembrane glycoprotein E1, J. Virol. 62:8.

Chasey, D., and Alexander, D. J., 1976. Morphogenesis of avian infectious bronchitis virus in primary chick kidney cells, Arch. Virol. 52:101.

Collins, A. R., Knobler, R. L., Powell, H., and Buchmeier, M. J., 1982, Monoclonal antibodies to murine hepatitis virus 4 (strain JHM) define the viral glycoprotein responsible for attachment and cell-cell fusion, Virology 119:358.

David-Ferreira, J. F., and Manaker, R. A., 1965, An electron microscope study of the development of a mouse hepatitis virus in tissue culture cells, J. Cell Biol. 24:57.

Deregt, D., and Babiuk, L. A., 1987, Monoclonal antibodies to bovine coronavirus: Characteristics and topographical mapping of neutralizing epitopes on the E2 and E3 glycoproteins, Virology 161:410.

Deregt, D., Sabara, M., and Babiuk, L. A., 1987, Structural proteins of bovine coronavirus and their intracellular processing, J. Gen. Virol. 68:2863.

Doyle, C., Sambrook, J., and Gething, M.-J., 1986, Analysis of progressive deletions of the transmembrane and cytoplasmic domains of influenza hemagglutinin, J. Cell Biol. 103:1193.

Dubois-Dalcq, M. E., Doller, E. W., Haspel, M. V., and Holmes, K. V., 1982, Cell tropism and expression of mouse hepatitis viruses (MHV) in mouse spinal cord cultures, Virology 119:317.

Dubois-Dalcq, M. E., Holmes, K. V., and Rentier, B., 1984, Assembly of RNA Viruses, Springer Verlag, New York. 
Earl, P. L., Moss, B., and Doms, R. W., 1991, Folding, interaction with GRP78-BiP, assembly, and transport of the human immunodeficiency virus type 1 envelope protein, $J$. Virol. 65:2047.

Fiscus, S. A., and Teramoto, Y. A., 1987, Antigenic comparison of feline coronavirus isolates: Evidence for markedly different peplomer glycoproteins, J. Virol. 61:2607.

Fleming, J. O., Shubin, R. A., Sussman, M. A., Casteel, N., and Stohlman, S. A., 1989, Monoclonal antibodies to the matrix (E1) glycoprotein of mouse hepatitis virus protect mice from encephalitis, Virology 168:162.

Gallagher, T. M., Parker, S. E., and Buchmeier, M. J., 1990, Neutralization-resistant variants of the neurotropic coronavirus are generated by deletions within the amino-terminal half of the spike glycoprotein, $J$. Virol. 64:731.

Garwes, D. J., Pocock, D. H., and Pike, B. V., 1976, Isolation of subviral components from transmissible gastroenteritis virus, J. Gen. Virol. 32:283.

Geyer, H., Holschbach, C., Hunsmann, G., and Schneider, J., 1988, Carbohydrates of human immunodeficiency virus. Structures of olisosaccharides linked to the envelope glycoprotein 120, J. Biol. Chem. 263:11760.

Hasony, H. J., and Macnaughton, M. R., 1981, Antigenicity of mouse hepatitis virus strain 3 subcomponents in C57 strain mice, Arch. Virol. 69:33.

Hauri, H.-P., and Schweizer, A., 1992, The endoplasmic reticulum-Golgi intermediate compartment, Curr. Opin. Cell Biol. 4:600.

Hogue, B. G., and Brian, D. A., 1986, Structural proteins of human respiratory coronavirus OC43, Virus Res. 5:131.

Holmes, K. V., and Behnke, J. N., 1981, Evolution of a coronavirus during persistent infection in vitro, Adv. Exp. Med. Biol. 142:287.

Holmes, K. V., Doller, E. W., and Behnke, J. N., 1981a, Analysis of the functions of coronavirus glycoproteins by differential inhibition of synthesis with tunicamycin, $A d v$. Exp. Med. Biol. 142:133.

Holmes, K. V., Doller, E. W., and Sturman, L. S., 1981b, Tunicamycin resistant glycosylation of a coronavirus glycoprotein: Demonstration of a novel type of viral glycoprotein, Virology 115:334.

Horsburgh, B. C., Brierley, I., and Brown, T. D. K., 1992, Analysis of a $9.6 \mathrm{~kb}$ sequence from the 3' end of canine coronavirus genomic RNA, J. Gen. Virol. 73:2849.

Horzinek, M. C., Lutz, H., and Pedersen, N. C., 1982, Antigenic relationships among homologous structural polypeptides of porcine, feline, and canine coronaviruses. Infect, Immunology 37:1148.

Jacobs, L., Van der Zeijst, B. A. M., and Horzinek, M. C., 1986, Characterization and translation of transmissible gastroenteritis virus mRNAs, J. Virol. 57:1010.

Kapke, P. A., Tung, F. Y. T., Hogue, B. G., Brian, D. A., Woods, R. D., and Wesley, R., 1988, The amino-terminal signal peptide on the porcine transmissible gastroenteritis coronavirus matrix protein is not an absolute requirement for membrane translocation and glycosylation, Virology 165:367.

King, B., and Brian, D. A., 1982, Bovine coronavirus structural proteins, J. Virol. 42:700.

Klumperman, J., Krijnse Locker, J., Meijer, A., Horzinek, M. C., Geuze, H. J., and Rottier, P. J. M., 1994, Coronavirus M proteins accumulate in the Golgi complex beyond the site of virion budding, J. Virol. 68:6523.

Krijnse Locker, J., Griffiths, G., Horzinek, M. C., and Rottier, P. J. M., 1992a, O-glycosylation of the coronavirus M protein, I. Biol. Chem. 267:14094.

Krijnse Locker, J., Rose, J. K., Horzinek, M. C., and Rottier, P. J. M., 1992b, Membrane assembly of the triple-spanning coronavirus M protein, J. Biol. Chem. 267:21911.

Krijnse Locker, J., Ericsson, M., Rottier, P. J. M., and Griffiths, G., 1994, Characterization of the budding compartment of mouse hepatitis virus, J. Cell Biol. 124:55.

Krijnse Locker, J., Klumperman, J., Oorschot, V., Geuze, H. J., Horzinek, M. C., and Rottier, P. J. M., 1995, The cytoplasmic tail of mouse hepatitis virus $M$ protein is essential but not sufficient for its retention in the Golgi complex, J. Biol. Chem. 269:28263.

Kyte, J., and Doolittle, R. F., 1982, A simple method for displaying the hydropathic character of a protein, J. Mol. Biol. 157:105.

Lanser, J. A., and Howard, C. R., 1980, The polypeptides of infectious bronchitis virus (IBV-41 strain). J. Gen. Virol. 46:349. 
Lapps, W., Hogue, B. G., and Brian, D. A., 1987, Sequence analysis of the bovine coronavirus nucleocapsid and matrix protein genes, Virology 157:47.

Laude, H., Chapsal, J.-M., Gelfi, J., Labiau, S., and Grosclaude, J., 1986, Antigenic structure of transmissible gastroenteritis virus. I. Properties of monoclonal antibodies directed against virion proteins, I. Gen. Virol. 67:119.

Laude, H., Rasschaert, D., and Huet, J.-C., 1987, Sequence and N-terminal processing of the transmissible protein $\mathrm{El}$ of the coronavirus transmissible gastroenteritis virus, J. Gen. Virol. 68:1687.

Laude, H., Gelfi, J., Lavenant, L., and Charley, B., 1992, Single amino acid changes in the viral glycoprotein $M$ affect induction of alpha interferon by the coronavirus transmissible gastroenteritis virus, $J$. Virol. 66:743.

Laviada, M. D., Videgain, S. P., Moreno, L., Alonso, F., Enjuanes, L., and Escribano, J. M., 1990, Expression of swine transmissible gastroenteritis virus envelope antigens on the surface of infected cells: Epitopes externally exposed, Virus Res. 16:247.

Luytjes, W., Sturman, L. S., Bredenbeek, P. J., Charité, J., Van der Zeijst, B. A. M., Horzinek, M. C., and Spaan, W. J. M., 1987, Primary structure of the glycoprotein E2 of coronavirus MHV-A59 and identification of the trypsin cleavage site, Virology 161:479.

Machamer, C. E., and Rose, J. K., 1987, A specific transmembrane domain of a coronavirus E1 glycoprotein is required for its retention in the Golgi region, J. Cell Biol. 105:1205.

Machamer, C. E., Mentone, S. A., Rose, J. K., and Farquhar, M. G., 1990, The E1 glycoprotein of an avian coronavirus is targeted to the cis Golgi complex, Proc. Nat1. Acad. Sci. USA 87:6944.

Machamer, C. E., Grim, M. G., Esquela, A., Chung, S. W., Rolls, M., Ryan, K., and Swift, A. M., 1993, Retention of a cis Golgi protein requires polar residues on one face of a predicted $\alpha$-helix in the transmembrane domain, Mol. Biol. Cell 4:695.

Macnaughton, M. R., 1981, Structural and antigenic relationships between human, murine and avian coronaviruses, Adv. Exp. Med. Biol. 142:19.

Mayer, T., Tamura, T., Falk, M., and Niemann, H., 1988, Membrane integration and intracellular transport of the coronavirus glycoprotein E1, a class III membrane glycoprotein, J. Biol. Chem. 263:14956.

McIntosh, K., Kapikian, A. Z., Hardison, K. A., Hartley, J. W., and Chanock, R. M., 1969, Antigenic relationships among the coronaviruses of man and between human and animal coronaviruses, J. Immunol. 102:1109.

Mobley, J., Evans, G., Dailey, M. O., and Perlman, S., 1992, Immune response to a murine coronavirus: Identification of a homing receptor-negative $\mathrm{CD} 4^{+} \mathrm{T}$ cell subset that responds to viral glycoproteins, Virology 187:443.

Mounir, S., and Talbot, P. J., 1992, Sequence analysis of the membrane protein gene of human coronavirus OC43 and evidence for O-glycosylation, J. Gen. Virol. 73:2731.

Niemann, H., and Klenk, H.-D., 1981, Coronavirus glycoprotein El, a new type of viral glycoprotein, J. Mol. Biol. 153:993.

Niemann, H., Boschek, B., Evans, D., Rosing, M., Tamura, T., and Klenk, H.-D., 1982, Post-translational glycosylation of coronavirus glycoprotein E1: Inhibition by monensin, EMBO J. 1:1499.

Niemann, H., Geyer, R., Klenk, H.-D., Linder, D., Stirm, S., and Wirth, M., 1984, The carbohydrates of mouse hepatitis virus (MHV) A59: Structures of the O-glycosidically linked oligosaccharides of glycoprotein E1, EMBO J. 3:665.

Opstelten, D.-J. E., Horzinek, M. C., and Rottier, P. J. M., 1993a, Complex formation between the spike protein and the membrane protein during mouse hepatitis virus assembly, $A d v$. Exp. Med. Biol. 342:189.

Opstelten, D.-J. E., De Groote, P., Horzinek, M. C., Vennema, H., and Rottier, P. J. M., 1993b, Disulfide bonds in folding and transport of mouse hepatitis coronavirus glycoproteins, $J$. Virol. 67:7394.

Opstelten, D.-J. E., De Groote, P., Horzinek, M. C., and Rottier, P. J. M., 1994, Folding of the mouse hepatitis virus spike protein and its association with the membrane protein, Arch. Virol. (Suppl) 9:319.

Parker, S. E., Gallagher, T. M., and Buchmeier, M. J., 1989, Sequence analysis reveals extensive polymorphism and evidence of deletions within the E2 glycoprotein gene of several strains of murine hepatitis virus, Virology 173:664. 
Pedersen, N. C., Ward, I., and Mengeling, W. L., 1978, Antigenic relationships of the feline infectious peritonitis virus to coronaviruses of other species, Arch. Virol. 58:45.

Pfleiderer, M., Skinner, M. A., and Siddell, S. G., 1986, Coronavirus MHV-JHM: Nucleotide sequence of the mRNA that encodes the membrane protein, Nucleic Acids Res. 14:6338.

Pulford, D. J., and Britton, P., 1990, Expression and cellular localisation of porcine transmissible gastroenteritis virus $N$ and $M$ proteins by recombinant vaccinia viruses, Virus Res. 18:203.

Raabe, T., and Siddell, S. G., 1989, Nucleotide sequence of the gene encoding the membrane protein of human coronavirus $229 \mathrm{E}$, Arch. Virol. 107:323.

Rasschaert, D., Duarte, M., and Laude, H., 1990, Porcine respiratory coronavirus differs from transmissible gastroenteritis virus by a few genomic deletions, J. Gen. Virol. 71:2599.

Rottier, P. J. M., and Rose, J. K., 1987, Coronavirus El glycoprotein expressed from cloned cDNA localizes in the Golgi region, J. Virol. 61:2042.

Rottier, P. J. M., Spaan, W. J. M., Horzinek, M. C., and Van der Zeijst, B. A. M., 1981a, Translation of three mouse hepatitis virus strain A59 subgenomic RNAs in Xenopus laevis oocytes, $J$. Virol. 38:20.

Rottier, P. J. M., Horzinek, M. C., and Van der Zeijst, B. A. M., 1981b, Viral protein synthesis in mouse hepatitis virus strain A59-infected cells: Effect of tunicamycin, J. Virol. 40:350.

Rottier, P., Brandenburg, D., Armstrong, J., Van der Zeijst, B., and Warren, G., 1984, Assembly in vitro of a spanning membrane protein of the endoplasmic reticulum: The E1 glycoprotein of coronavirus mouse hepatitis virus A59, Proc. Natl. Acad. Sci. USA 81:1421.

Rottier, P., Armstrong, J., and Meyer, D. I., 1985, Signal recognition particle-dependent insertion of coronavirus E1, an intracellular membrane glycoprotein, J. Biol. Chem. 260:4648.

Rottier, P. J. M., Welling, G. W., Welling-Wester, S., Niesters, H. G. M., Lenstra, J. A., and Van der Zeijst, B. A. M., 1986, Predicted membrane topology of the coronavirus protein E1, Biochemistry 25:1335.

Rottier, P. J. M., Krijnse Locker, J., Horzinek, M. C., and Spaan, W. J. M., 1990, Expression of MHVA59 M glycoprotein: Effects of deletions on membrane integration and intracellular transport, Adv. Exp. Med. Biol. 276:127.

Sanchez, C. M., Jimenez, G., Laviada, M. D., Correa, I., Sune, C., Bullido, M. J., Gebauer, F., Smerdou, C., Callebaut, P., Escribano, J. M., and Enjuanes, L., 1990, Antigenic homology among coronaviruses related to transmissible gastroenteritis virus, Virology 174:410.

Schmidt, I., Skinner, M., and Siddell, S., 1987, Nucleotide sequence of the gene encoding the surface projection glycoprotein of coronavirus MHV-JHM, J. Gen. Virol. 68:47.

Schmidt, M. F. G., 1982, Acylation of viral spike glycoproteins, a feature of enveloped RNA viruses, Virology 116:327.

Schmidt, O. W., and Kenny, G. E., 1982, Polypeptides and functions of antigens from human coronaviruses 229E and OC43, Infect. Immun. 35:515.

Siddell, S. G., Wege, H., Barthel, A., and Ter Meulen, V., 1981, Coronavirus JHM. Intracellular protein synthesis, J. Gen. Virol. 53:145.

Stern, D. F., and Sefton, B. M., 1982a, Coronavirus proteins: Biogenesis of avian infectious bronchitis virus virion proteins, $J$. Virol. 44:794.

Stern, D. F., and Sefton, B. M., 1982b, Coronavirus proteins: Structure and function of the oligosaccharides of the avian infectious bronchitis virus glycoproteins, $J$. Virol. 44:804.

Stern, D. F., Burgess, L., and Sefton, B. M., 1982, Structural analysis of virion proteins of the avian coronavirus infectious bronchitis virus, J. Virol. 42:208.

Stohlman, S. A., and Lai, M. M. C., 1979, Phosphoproteins of murine hepatitis viruses, I. Virol. 32:672.

Sturman, L. S., 1977, Characterization of a coronavirus. I. Structural proteins: Effects of preparative conditions on the migration of protein in polyacrylamide gels, Virology 77:637.

Sturman, L. S., 1981, The structure and behaviour of coronavirus A59 glycoproteins, Adv. Exp. Med. Biol. 142:1.

Sturman, L. S., and Holmes, K. V., 1977, Characterization of a coronavirus. II. Glycoproteins of the viral envelope: Tryptic peptide analysis, Virology 77:650.

Sturman, L. S., Holmes, K. V., and Behnke, J., 1980, Isolation of coronavirus envelope glycoproteins and interaction with the viral nucleocapsid, $J$. Virol. 33:449.

Sugiyama, K., and Amano, Y., 1981, Morphological and biological properties of a new coronavirus associated with diarrhea in infant mice, Arch. Virol. 67:241. 
Swift, A. M., and Machamer, C. E., 1991, A Golgi retention signal in a membrane-spanning domain of coronavirus El protein, J. Cell Biol. 115:19.

Tooze, J., Tooze, S., and Warren, G., 1984, Replication of coronavirus MHV-A59 in sac- cells: Determination of the first site of budding of progeny virions, Eur. J. Cell Biol. 33:281.

Tooze, J., Tooze, S. A., and Warren, G., 1985, Laminated cisternae of the rough endoplasmic reticulum induced by coronavirus MHV-A59 infection, Eur. J. Cell Biol. 36:108.

Tooze, J., Tooze, S. A., and Fuller, S. D., 1987, Sorting of progeny coronavirus from condensed secretory proteins at the exit from the trans-Golgi network of AtT20 cells, J. Cell Biol. 105:1215.

Tooze, S. A., and Stanley, K. K., 1986, Identification of two epitopes in the carboxyterminal 15 amino acids of the E1 glycoprotein of mouse hepatitis virus A59 by using hybrid proteins, I. Virol. 60:928.

Tooze, S. A., Tooze, J., and Warren, G., 1988, Site of addition of $N$-acetyl-galactosamine to the El glycoprotein of mouse hepatitis virus-A59, J. Cell. Biol. 106:1475.

Vennema, H., De Groot, R. J., Harbour, D. A., Dalderup, M., Gruffydd-Jones, T., Horzinek, M. C., and Spaan, W. J. M., 1990a, Early death after feline infectious peritonitis virus challenge due to recombinant vaccinia virus immunization, $J$. Virol. 64:1407.

Vennema, H., Heijnen, L., Zijderveld, A., Horzinek, M. C., and Spaan, W. J. M., 1990b, Intracellular transport of recombinant coronavirus spike proteins: Implications for virus assembly, $J$. Virol. 64:339.

Vennema, H., De Groot, R. J., Harbour, D. A., Horzinek, M. C., and Spaan, W. J. M., 1991a, Primary structure of the membrane and nucleocapsid protein genes of feline infectious peritonitis virus and immunogenicity of recombinant vaccinia viruses in kittens, Virology 181:327.

Vennema, H., Rijnbrand, R., Heijnen, L., Horzinek, M. C., and Spaan, W. J. M., 1991b, Enhancement of the vaccinia virus/phage T7 RNA polymerase expression system using encephalomyocarditis virus 5'-untranslated region sequences, Gene 108:201.

Verbeek, A., and Tijssen, P., 1991, Sequence analysis of the turkey enteric coronavirus nucleocapsid and membrane protein genes: A close genomic relationship with bovine coronavirus, J. Gen. Virol. 72:1659.

Wang, F.-I., Fleming, J. O., and Lai, M. M. C., 1992, Sequence analysis of the spike protein gene of murine coronavirus variants: Study of genetic sites affecting neuropathogenicity, Virology 186: 742 .

Wege, H., Wege, H., Nagashima, K., and Ter Meulen, V., 1979, Structural polypeptides of the murine coronavirus JHM, J. Gen. Virol. 42:37.

Weisz, O. A., Swift, A. M., and Machamer, C. E., 1993, Oligomerization of a membrane protein correlates with its retention in the Golgi complex, J. Cell Biol. 122:1185.

Wesseling, J. G., Godeke, G.-J., Schijns, V. E. C. J., Prevec, L., Graham, F. L., Horzinek, M. C., and Rottier, P. J. M., 1993, Mouse hepatitis virus spike and nucleocapsid proteins expressed by adenovirus vectors protect mice against a lethal infection, J. Gen. Virol. 74:2061.

Wesseling, J. G., Vennema, H., Godeke, G.-J., Horzinek, M. C., and Rottier, P. J. M., 1994, Nucleotide sequence and expression of the spike (S) gene of canine coronavirus and comparison with the $S$ proteins of feline and porcine coronaviruses, J. Gen. Virol. 75:1789.

Woods, R. D., Wesley, R. D., and Kapke, P. A., 1988, Neutralization of porcine transmissible gastroenteritis virus by complement-dependent monoclonal antibodies, Am. J. Vet. Res. 49:300. 